\title{
Política, futebol e mito em miniatura: Fealdade de Fabiano Gorila, de Marcello Quintanilha
}

\author{
Politics, Football and Myth en Miniature: \\ Marcello Quintanilha's Fealdade de Fabiano Gorila
}

\author{
Marcel Vejmelka \\ Universidade de Mainz/Alemanha \\ Doutor em Estudos latino-americanos/brasileiros, Freie Universität Berlin \\ vejmelka@uni-mainz.de
}

\begin{abstract}
RESUMo: Na representação artística e na reflexão crítica, o futebol entra no domínio do "mito" cultural, onde simbolismos e significados passam a funcionar de maneira indireta e indeterminada, como explica Klaus Theweleit (2004). Em Fealdade de Fabiano Gorila, uma espécie de "conto gráfico" publicado em 1999, Marcello Quintanilha combina a trajetória individual de um jogador de futebol com a evolução histórica do jogo em meados dos anos 1950 e com o destino político do Brasil. Combinando a arte visual em geral com as técnicas específicas das histórias em quadrinhos e com a dimensão narrativa tradicional, Quintanilha cria uma miniatura dentro da qual é possível identificar alguns momentos de mudança dentro do jogo que permitem analisar a evolução político-social do Brasil, e viceversa, momentos de transformação política que vão repercutir no futebol.
\end{abstract}

PalaVRAs-ChaVE: Marcello Quintanilha; Narrativa gráfica; Romance gráfico; Times de fábrica; Mitos modernos.

ABSTRACT: In its artistic representation and critical reflection, football enters the realm of cultural "myth", where symbolisms and significations work in an indirect and undetermined way, according to Klaus Theweleit (2004). In Fealdade de Fabiano Gorila, a kind of "graphic short story", published in 1999, Marcello Quintanilha combines the individual career of a football player and the historical development of the game and Brazil's political fate in the 1950s. Quintanilha merges visual art with specific techniques of comics and with traditional storytelling, and creates a miniature within which it is possible to identify moments of change of the game that refer to the socio-political evolution in Brazil. and vice-versa, moments of political transformation that will have their effect on football.

KEYWORDS: Marcello Quintanilha; Graphic narrative; Graphic novel; Company teams; Modern myths. 


\section{O MITO MODERNO}

Na introdução ao seu exaustivo e já clássico estudo sobre a profissionalização do futebol alemão na segunda metade do Século XX - cujo título Samstags um halb vier (Sábado, três e meia) evoca um lugar de memória e mito moderno da Alemanha do pós-guerra -, Nils Havemann define o futebol como objeto ideal para a pesquisa com profundidade histórica:

As conversas, os papos de "entendidos" e debates sobre futebol, que ocorrem praticamente em todos os níveis, dizem menos sobre o jogo do que sobre os humores, as necessidades e a condição mental de uma sociedade. Ao entrelaçar este mundo das narrativas, interpretações e dos significados com o nível dos atores e do respectivo pano de fundo histórico, surgem as suas enormes possibilidades: tal percepção torna o esporte em objeto de estudo ideal para explorar a evolução histórica de sociedades com as suas normas, valores e ideais em transformação contínua. ${ }^{1}$

Quero a seguir explorar um pouco o duplo significado do conceito de "narrativa", a partir desta citação. Havemann entende como narrativas a totalidade do discurso futebolístico na mídia, nas expressões da cultural popular e no dia-a-dia do público. Ao mesmo tempo, ele se refere ao significado mais "literário" do termo, a essa qualidade ensaística ou ficcional que muita conversa, discussão e reflexão sobre partidos, campeonatos e jogadores de futebol implica e produz. E assim nos faz refletir sobre o potencial de significação do trabalho consciente e tecnicamente "narrativo" que se baseia nessas expressões cotidianas.

Com isso, a narrativa artística - literária, cinematográfica, audiovisual ou, no caso aqui estudado, gráfica-sequencial da HQ - é particularmente capaz de explorar outra dupla significação, originária da importância sociocultural do futebol, que é a do mito moderno. Porque na representação artística e na reflexão crítica, o futebol entra o domínio do "mito" cultural, onde simbolismos e

\footnotetext{
${ }^{1}$ HAVEMANN. Samstags um halb 4, p. 8. „Die auf nahezu allen Ebenen geführten Gespräche, Fachsimpeleien und Debatten über Fußball sagen weniger etwas über das Spiel als über die Stimmungen, Bedürfnisse und geistige Verfassung einer Gesellschaft aus. Wenn man diese Welt der Erzählungen, Deutungen und Sinnbezüge eng mit der Ebene der handelnden Akteure und des jeweiligen geschichtlichen Hintergrunds verwebt, offenbaren sich die enormen Möglichkeiten: Ein solcher Zugriff macht den Sport zu einem idealen Untersuchungsgegenstand, um historische Wandlungsprozesse von Gesellschaften mit ihren sich kontinuierlich verändernden Normen, Werten und Leitvorstellungen zu ergründen“"
} 
significados passam a funcionar de maneira indireta e indeterminada, como explica Klaus Theleweit no seu estudo do futebol como "modelo de realidade":

Quem perceber o que e quando muda no futebol, por osmose, está informado sobre outras áreas da sociedade. [...] Onde o significado político real de algo desaparece - e quando se quer preservá-lo -, surge o mito no seu lugar. 0 futebol, o mundo político e a cultura pop estão cheios desses mitos. ${ }^{2}$

Agora, no caso do futebol brasileiro, os termos "mito" e "mitificação" adquirem um significado ainda mais urgente e denso, dada a extraordinária importância do jogo no imaginário local, regional e nacional. Leonel Kaz e Paulo Costa e Silva encontraram uma formulação, no meu modo de entender, muito feliz e expressiva para esta qualidade excepcional da mitologia futebolística brasileira:

No Brasil, o mito do futebol [...] surgiu como potência e diferença justamente no momento em que se articulava, no país tardoescravocrata, a nova imagem, partilhada por intelectuais da elite e pelo povo, do Brasil moderno, popular e mulato. Seria pouco dizer que o futebol, junto com a música popular, tornou-se a partir daí um dos pilares fundamentais desse mito. Melhor seria dizer que ele se confundiu de tal modo com esse mito que o mito passou a ser ele. ${ }^{3}$

E para explorar todo o potencial que proporciona esta percepção do futebol enquanto mito na cultura pop e popular, quando este serve como objeto de análise refletida, convém lembrar a ligação estreita dele com o conhecido conceito cunhado por Roland Barthes em Mythologies (livro publicado em 1957, com textos escritos entre 1954 1955), onde descreve o mito moderno como "sistema semiológico segundo" ("système sémiologique second").4

Na sua definição bem conhecida, Barthes explica que esta forma de mito moderno "naturaliza" o que, na verdade, é História:

Atingimos assim o próprio princípio do mito: transforma a história em natureza. [...] tudo se passa como se a imagem provocasse naturalmente o conceito e o significante criasse o significado: o mito existe a partir do

\footnotetext{
${ }^{2}$ THELEWEIT. Tor zur Welt, p. 116. "Wer mitbekommt, was sich im Fußball wann und wie verschiebt, ist über andere Gesellschaftsbereiche osmotisch informiert. [...] Wo die reale politische Bedeutung einer Sache schwindet, tritt - wenn man sie bewahren will - ein Mythos an ihre Stelle. Fußball, politische Welt, Popwelt sind voll von solchen Mythen."

${ }^{3}$ KAZ; COSTA E SILVA. Dando tratos à bola: futebol e Brasil, p. 77-78.

${ }^{4}$ BARTHES. Mythologies, p. 218.
} 
momento preciso em que a imperialidade francesa adquire um estatuto natural: o mito é uma fala excessivamente justificada. 5

Eu gostaria de ilustrar este mecanismo com um exemplo que me ocorreu

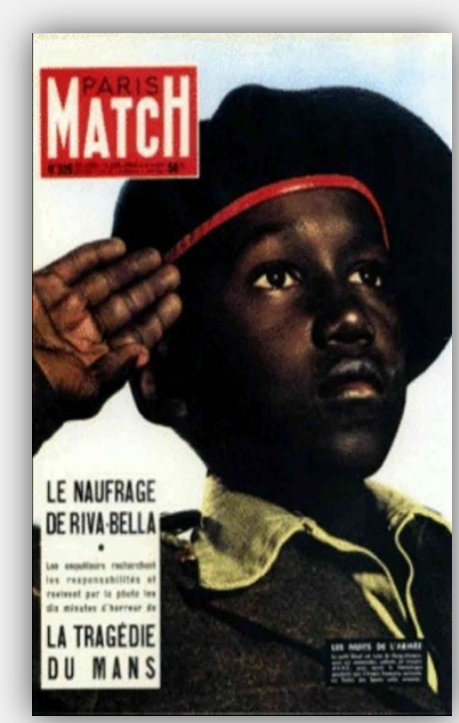
por acaso - ou justamente não por acaso - uma semana antes do congresso em que apresentei a comunicação que deu origem a este texto. Em Mythologies, Roland Barthes comenta a famosa capa da revista Paris Match (de 25 de junho de 1955), explicando como funciona o mito da identificação do jovem soldado negro ali retratado com o Império Francês, sem que para isso se precisasse de comentários verbais ou explicações explícitas.

A capa da edição especial da revista alemã de futebol 11 Freunde, publicada em setembro de 2019 e dedicada ao tema "Liebe \& Hass" ("Amor \& Ódio"), traz uma fotografia de Pelé e Garrincha se abraçando no gramado depois da final da copa do mundo de 1958 na Suécia. Também ali, sem necessidade de comentários e explicações, na comunicação visual com o público alemão, esta fotografia põe em funcionamento o mito do futebol brasileiro tricampeão do mundo, personificado por seus dois craques por excelência no momento de sua primeira consagração internacional. 0 único elemento

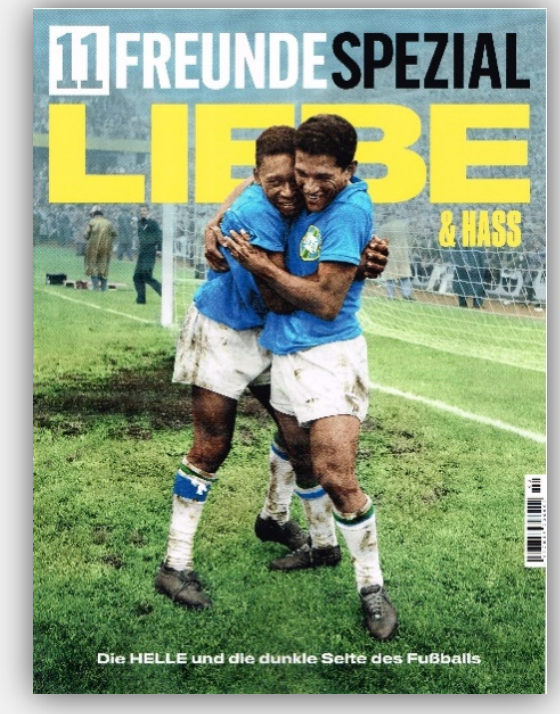
gráfico adicionado para intensificar este efeito é o fato da fotografia, que originalmente era em preto e branco, posteriormente ter sido colorida, para dar

\footnotetext{
${ }^{5}$ BARTHES. Mitologias, p. 221. "Nous sommes ici au principe même du mythe ; il transforme I'histoire en nature. [...] tout se passe comme si l'image provoquait naturellement le concept, comme si le signifiant fondait le signifié: le mythe existe à partir du moment précis où impérialité française passe à l'état de nature : le mythe est une parole excessivement justifiée." (BARTHES, Mythologies, p. 236-237)
} 
destaque ao azul da camisa brasileira, evidenciando como funciona esta mitologia barthiana, inclusive na Alemanha de hoje, a respeito do futebol brasileiro.

A parole enquanto enunciação linguístico-discursiva é a dimensão onde se realiza o sobre-carregamento significativo e simbólico do elemento em questão, do significado através do significante. Em outro momento, Barthes reflexiona sobre os meios e as expressões de tais mitologias, particularmente na relação entre palavra e imagem, parole e imaginário:

[0] mito é uma fala escolhida pela História: não poderia de modo algum surgir da "natureza" das coisas.

Esta fala é uma mensagem. Pode, portanto, não ser oral; pode ser formada por escritas ou representações: o discurso escrito, assim como a fotografia, o cinema, a reportagem, o esporte, os espetáculos, a publicidade, tudo isso pode servir de apoio à fala mítica. [...] a imagem é certamente mais imperativa do que a escrita, impondo a significação de uma só vez, sem analisá-la e dispersá-la. Mas isso já não é uma diferença constitutiva. A imagem se transforma numa escrita, a partir do momento em que é significativa: como a escrita, ela exige uma lexis. ${ }^{6}$

Tal como, para Barthes, um mito francês no domínio do esporte é o Tour de France, não é difícil conceber, a partir dessas reflexões, o futebol (em si) como um mito fundamental do Brasil moderno, manifesto e detectável nas mais variadas formas de representação, como acabamos de ler no texto barthiano.

\section{O MITO EM MINIATURA}

Em Fealdade de Fabiano Gorila, uma espécie de 'conto gráfico' publicado em 19997, Marcello Quintanilha combina a trajetória individual de um jogador de futebol

\footnotetext{
${ }^{6}$ BARTHES, Mitologias, p. 200-201. "[L]e mythe est une parole choisie par l'histoire: il ne saurait surgir de la « nature » des choses.

"Cette parole est un message. Elle peut donc être bien autre chose qu'orale; elle peut être formée d'écritures ou de représentations: le discours écrit, mais aussi la photographie, le cinéma, le reportage, le sport, les spectacles, la publicité, tout cela peut servir de support à la parole mythique. [...] l'image est, certes, plus impérative que l'écriture, elle impose la signification d'un coup, sans l'analyser, sans la dispenser. Mais ceci n'est plus une différence constitutive. L'image devient une écriture, dès l'instant qu'elle est significative : comme l'écriture, elle appelle une lexis !" (BARTHES, Mythologies, p. 212-213)

${ }^{7}$ Então sob o pseudônimo de Marcello Gaú (São Paulo, editora Conrad), em 2011 a obra foi incluída na coletânea Almas públicas (também pela editora Conrad) e para isso reformatada, com reordenação dos painéis (cf. PAIXÃO JÚNIOR / FRANCO, HISTORICIZAR SEMPRE!
} 
niteroiense com a evolução histórica do jogo em meados dos anos 1950 e com o destino político do Brasil naquele momento. Márcio Mário da Paixão Jr. e Edgar Silveira Franco, no único estudo exaustivo do conto gráfico que consegui encontrar por enquanto, resumem o projeto da seguinte forma:

Narrativa biográfica, foca a transferência do beque central do Manufatura para o Canto do Rio Futebol Clube. Pano de fundo: a morte de Getúlio Vargas.

A visualidade quadrinística criada pelo autor dá o tom da narrativa: o Rio de janeiro dos anos 50, o futebol, a vida no subúrbio. Quintanilha retrata tudo com precisão. Seu desenho possui uma abordagem eminentemente fotográfica. A opção pelo preto e branco acentua a sensação de nostalgia. Em Fealdade de Fabiano Gorila, as fronteiras entre ficção e documentário de diluem. ${ }^{8}$

Combinando a arte visual em geral com as técnicas específicas das histórias em quadrinhos e com a dimensão narrativa tradicional, Quintanilha cria uma miniatura dentro da qual - enquanto representação crítica do mito moderno barthiano - é possível identificar alguns momentos de mudança dentro do jogo que permitem analisar a evolução político-social do Brasil, e vice-versa, momentos de transformação política que vão repercutir no futebol. Fealdade de Fabiano Gorila capta e reproduz - pondo-as em evidência refletida, crítica - as imagens e a escrita do mito do futebol.

\section{“O DR. GETÚLIO MORREU!”}

O conto gráfico se centra no dia 24 de agosto de 1954, um dia de importância extraordinária na História brasileira, um dia que virou mito político e cultural refletido nos mais variados meios de expressão, ${ }^{9}$ por ter sido o dia do suicídio de Getúlio Vargas, ele mesmo um mito político brasileiro de importância fundamental.

ANACRONIZAR SEMPRE!). Eu utilizo a edição portuguesa publicada pela editora Polvo em 2016, como parte da renomada coleção "Romance gráfico brasileiro". Nesta coleção, aliás, foram editadas quase todas as obras de Quintanilha em Portugal.

${ }^{8}$ PAIXÃO JÚNIOR; FRANCO. HISTORICIZAR SEMPRE! ANACRONIZAR SEMPRE!, p. 105.

${ }^{9}$ Cf., por exemplo, o famoso romance Agosto, de Rubem Fonseca, de 1990, adaptado para uma minissérie do mesmo título pela Rede Globo em 1993. 
Feição e estrutura da pequena obra apontam para esta leitura, por exemplo com a

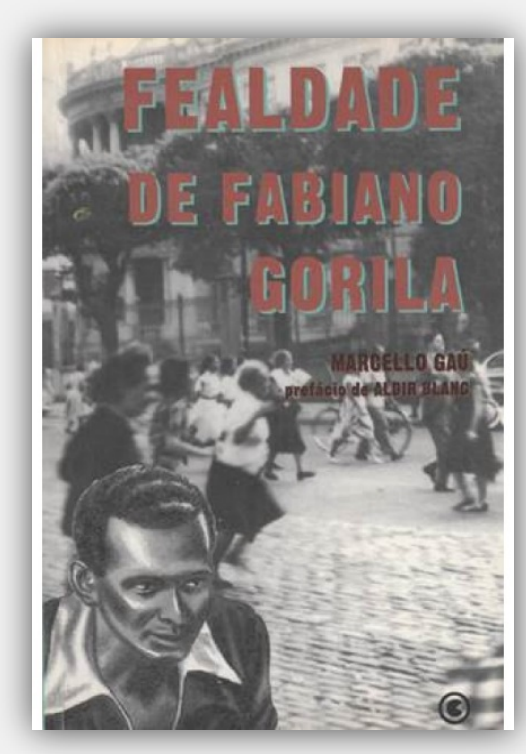
inserção de fotografias na capa, como se pode constatar na edição de 1999, assim como na contracapa e na orelha da edição de 2016.

Ainda 'fora' ou 'antes' da história propriamente dita, a edição portuguesa inclui cinco fotografias em estilo impressão de jornal amplificada (sempre ocupando as duas páginas opostas), formando uma espécie de 'prólogo', como, por exemplo, a transferência do corpo de Getúlio Vargas para São Borja em 25 de agosto. É a partir desta mitologia que uma e outra imagem lacônica, uma citação ou alusão visual, pode desencadear todo um complexo de significados históricos e políticos.

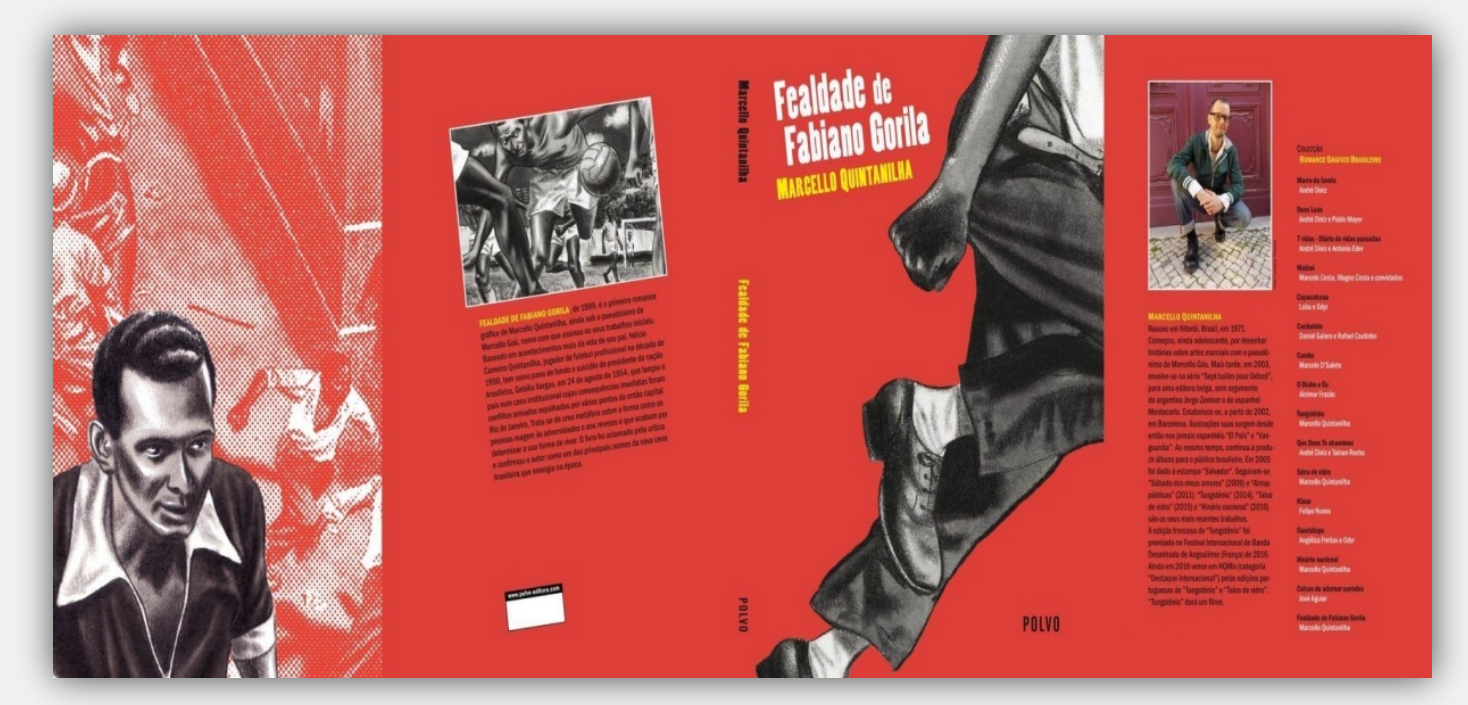

A cena de abertura - que se inicia com o corpo do protagonista correndo (cf. a imagem da capa da edição de 2016 acima) - nos informa sobre a morte de Getúlio Vargas, no contexto de um treino cancelado no centro do Fluminense FC e nos motiva a perguntar: 0 que termina e começa nesse dia, em termos da história do futebol brasileiro? 
Aqui não é o momento ou lugar para revisar toda a história do Getulismo relacionado com o futebol no Brasil. Para fins de situar a minha análise a partir da

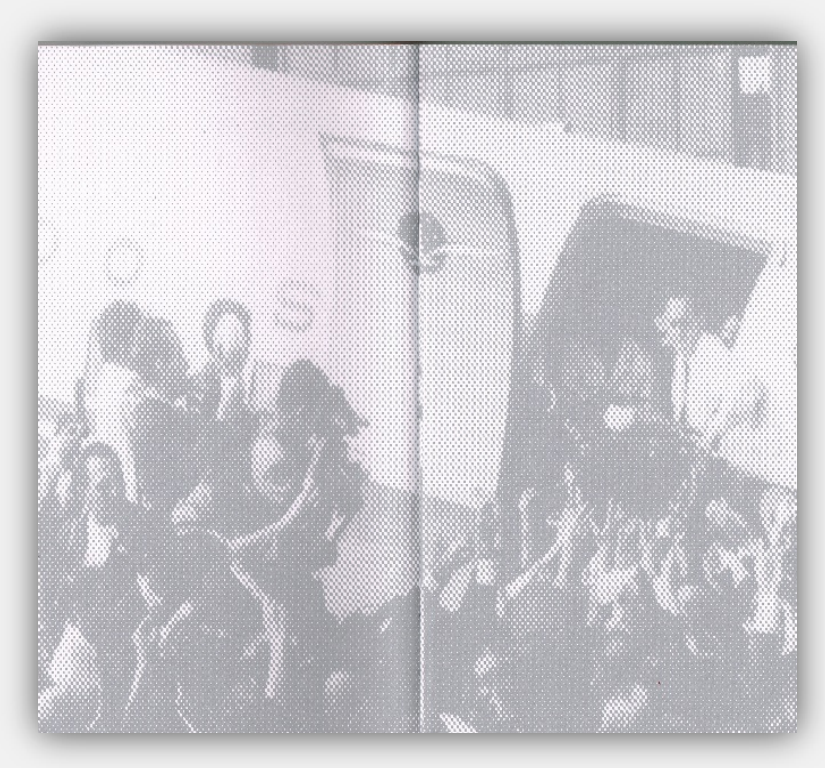
HQ, segue um resumo muito abreviado do que me parece relevante no momento evocado: $\mathrm{Na}$ relação entre o futebol e o (primeiro) governo de Getúlio Vargas, destaca-se nitidamente a profissionalização do jogo, processo que se iniciara nos anos 1920, mas que chegou a se consolidar e, principalmente, formalizar, com a legislação laboral decretada por Vargas em 1933. Daqui a pouco veremos como este aspecto joga um papel central em Fealdade de Fabiano Gorila. Outro aspecto sumamente importante, diretamente ligado ao primeiro, é o processo conjunto da "democratização" do jogo agora profissional, a sua nacionalização e a sua mitificação.

Ao assumir o governo, o novo presidente [Vargas, em 1930] apresenta seu projeto para melhorar o país, intitulado "Programa de Reconstrução Nacional", do qual constavam dezessete itens destacando as medidas mais urgentes e de aplicação imediata. [...] Assim que, dois anos depois, em 23 de janeiro de 1933, estaria definitivamente implantado o futebol profissional no Brasil, em que pese o comportamento amador de muitos dirigentes até hoje. Destaque-se, aqui, um aspecto significativo: reiterase com a profissionalização nos anos 20 o caráter e união e de identidade nacional através do futebol que, a essa altura, já estava definitivamente incorporado à cultura lúdica brasileira. ${ }^{10}$

Esta combinação bem caraterística do Estado Novo possibilita a profundidade histórica do tema tratado e representado na obra de Quintanilha. Ali, o complexo até hoje quase onipresente do "futebol mestiço" ou "futebol mulato" no Brasil não recebe destaque, entretanto, o enfoque na vida e carreira de um jogador

${ }^{10}$ CALDAS. Aspectos sociopolíticos do futebol brasileiro, p. 45. 
de futebol (quase) profissional só "funciona" - em termos narrativos e mitológicos - no contexto daquela "política cultural da brasilidade". ${ }^{11}$

0 mesmo vale para os momentos de importância histórica do futebol brasileiro entre 1930/37 a 1945 e 1951 a 1954, como a Copa Rio Branco, disputada esporadicamente entre o Uruguai e o Brasil a partir de 1931, a criação da Taça Rio-São Paulo em 1933 (para restabelecer a paz interna após a Revolução de 1932 (ou Guerra Paulista) de 1932, que marcam um aumento na relevância e projeção social do esporte, apoiado pela política de estado.

Em nível internacional, o evento mais marcante da época é a Copa de 1938 na França, onde o escrete brasileiro - com despedida oficial pelo Presidente e apadrinhado pela filha Alzira, com jogos transmitidos ao vivo na rádio e resumos posteriores no cinema - obtém o terceiro lugar e ganha a admiração e o respeito do público europeu. Artilheiro do torneio é Leônidas da Silva, primeiro craque brasileiro com visibilidade mundial e símbolo nacional da "democracia racial" projetada ao futebol.

Desde que a Copa do Mundo de 1950 foi realizada no Brasil e, também, no decorrer de toda a década, o país foi pressionado pelo movimento do capital estrangeiro, que resultou em mudanças estruturais significativas nos diferentes planos. No econômico, realizava-se a transição de uma sociedade agrícola para uma sociedade industrializada; no político, vivia-se o início do esgotamento de um discurso populista e a emergência de uma ideologia nacional-desenvolvimentista; e no cultural, ocorria um remodelamento dos diferentes segmentos, que visava incorporar e resolver a ambiguidade entre a tradição populista da cultura popular e a emergência de uma nova cultura de massa. ${ }^{12}$

Esta encruzilhada política (tanto nacional quanto global) se encontra condensada e refletida no dia 24 de agosto de 1954, tal como este é representado em Fealdade de Fabiano Gorila. Na vida real, é uma casualidade que o treino do pai de Marcello Quintanilha no Fluminense não tenha acontecido por causa dos acontecimentos políticos. Assim, e episódio 'cotidiano' de um simples cidadão podia servir de inspiração para o autor. No nível narrativo, esta casualidade se transforma em instrumento de reflexão das dimensões históricas que a provocaram e

\footnotetext{
${ }^{11}$ PRUTSCH; RODRIGUES-MOURA. Brasilien. Eine Kulturgeschichte, p. 131.

${ }^{12}$ FREITAS JÚNIOR. No meio do caminho, p. 6.
} 
acompanharam. Com o suicídio de Vargas e o fim de seu segundo governo, o Brasil chega à encruzilhada que levará à sua segunda Modernização, e o jogador que deve decidir em qual clube estará o seu futuro, representa o futebol nacional frente à sua definitiva profissionalização e comercialização.

De onde vem e para onde vai o futebol brasileiro, quando o focalizamos através desse dia? 0 início de carreira de um jogador de futebol serve de miniatura para refletir aspectos como a profissionalização do futebol, o mercado de jogadores, as práticas de transferência e as perspectivas de um jovem jogador, numa espécie de 'micropolítica' do futebol profissional, do mercado de jogadores, emprestando o conceito foucaultiano. ${ }^{13}$

\section{Atravessando o Rio}

A segunda cena acompanha Acir na sua fuga pelo centro do Rio de Janeiro para voltar a Niterói. Painéis e quadros muito dinâmicos encenam as suas correrias pelas ruas tumultuadas do Rio, por entre manifestantes, transeuntes e soldados, quase como dribles e tentativas de penetrar a defesa adversária num campo de futebol. ${ }^{14}$

Ao mesmo tempo, a inclusão de fotografias em estilo fotocópia transmite uma atmosfera documentária do momento histórico, entretanto, sem se posicionar a respeito dos motivos e objetivos dos acontecimentos retratados.

A dimensão política do futebol é evocada e também tematizada, entretanto, não a constelação política brasileira do momento histórico em questão. As manifestações e os tumultos nas ruas do Rio em reação à morte de Vargas não se atribuem a nenhum grupo político específico, nem carregam conteúdos, literalmente, constituem o pano de fundo para os acontecimentos que determinam a vida e carreira de um jogador de futebol. Não se reproduzem slogans, nem se veem cartazes ou faixas. Outro elemento famoso, as cartas "testamento" e

\footnotetext{
${ }^{13}$ Cf. FOUCAULT. Surveillir et punir.

${ }^{14}$ Em entrevista com Rafael Spaca, para a revista Bravo!, Quitanilha explica: "[...] as primeiras noções do meu conhecimento sobre anatomia e, principalmente, movimento, decorrem da observação sistemática das fotografias dos jogos de futebol impressas nos jornais dos anos 70 e 80, diante das quais eu passava horas e horas, tentando apreender ao máximo a mágica lógica da captura do instante preciso de um movimento, sem qualquer tipo de intencionalidade por parte das figuras ali representadas." (SPACA, "Não separo desenho e palavra").
} 
"despedida" de Vargas não aparecem nem se mencionam. O que os quadros mostram são tumultos e momentos de violência não especificados numa cidade que, esta sim, é retratada com muito detalhe e adequação histórica.

Um exemplo disso se vê na cena em que Acir passa pelo cinema Odeon na Cinelândia, onde está em cartaz o filme Meu filho, minha vida, na versão original

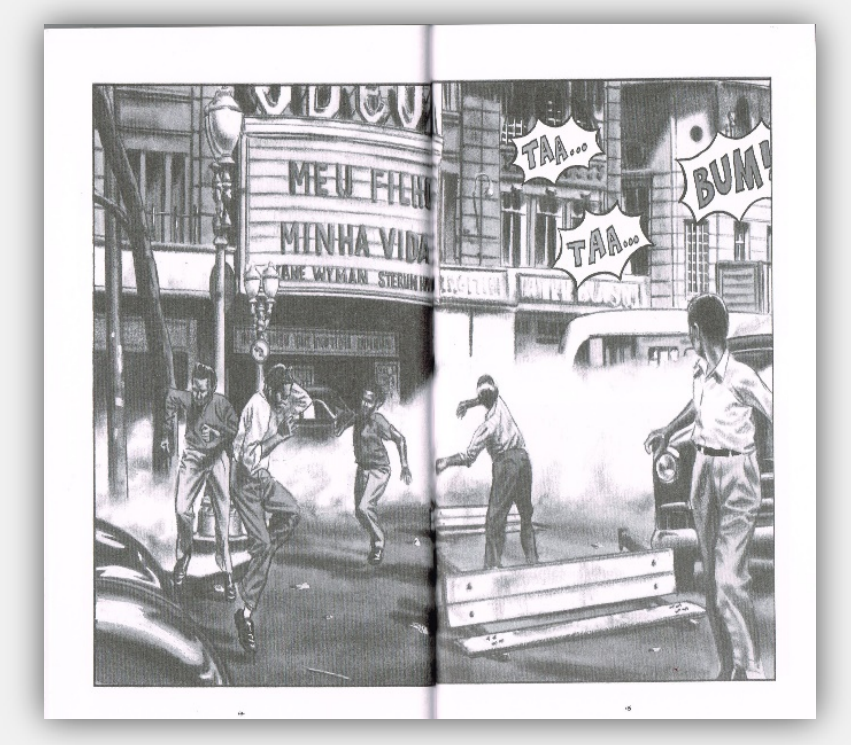
estado-unidense So big, de 1953, do diretor Robert Wise, com Jane Wyman e Sterun Hayden nos papéis principais. ${ }^{15}$

Também no meio de sua fuga pelo Rio, como em reminiscências do protagonista, ficamos sabendo que Acir joga no Manufatora A. C., um time de fábrica, o esquema de seu "emprego" é explicado utilizando a inserção de duas fotos entre os painéis desenhados, a fábrica e o time16, e - na análise de Paixão Jr. e Franco - "conferindo um aspecto documental à narrativa que sublinha seu efeito de realidade". ${ }^{17}$

Este curto momento remete à importância dos times de fábrica enquanto promotores históricos da profissionalização e democratização do futebol brasileiro, da integração social do esporte no nível local, nos bairros e subúrbios:

[A]lém de desenvolverem um profissionalismo próprio, singular, os clubes de fábrica mantinham uma estreita relação com o futebol profissional: revelavam atletas para os grandes clubes e os acolhiam quando abandonavam a profissão.

[...] Sua difusão em meio operário levou empresários a incentivarem a organização de clubes no interior das fábricas não apenas como forma de diversão e lazer: essas agremiações, ao participarem de campeonatos oficiais, divulgavam o nome da empresa e de seus produtos. A decorrente valorização do capital esportivo dos operários deu origem a um processo de mobilidade social no próprio local de trabalho, do qual

\footnotetext{
${ }^{15}$ QUINTANILHA, Fealdade de Fabiano Gorila, p. 44-45.

${ }^{16}$ QUINTANILHA, Fealdade de Fabiano Gorila, p. 22-23.

${ }^{17}$ PAIXÃO JÚNIOR / FRANCO, HISTORICIZAR SEMPRE! ANACRONIZAR SEMPRE!, p. 106.
} 
apenas uma pequena parcela de trabalhadores pôde ser beneficiada com ganhos reais. ${ }^{18}$

Além disso, os clubes de fábrica contribuíam para a implementação do mito do futebol no imaginário nacional brasileiro, a partir de suas bases locais e operárias:

Los clubes de fábrica, por ejemplo, configuraron un matriz esencial en el proceso de popularización y transformación del fútbol en un espectáculo. [...] El equipo de fútbol, la fábrica y la ciudad (barrio o núcleo obrero) constituían la densa trama en la que la comunidad se sentía representada y su éxito perduró hasta finales de los sesenta. ${ }^{19}$

A temática dos times de

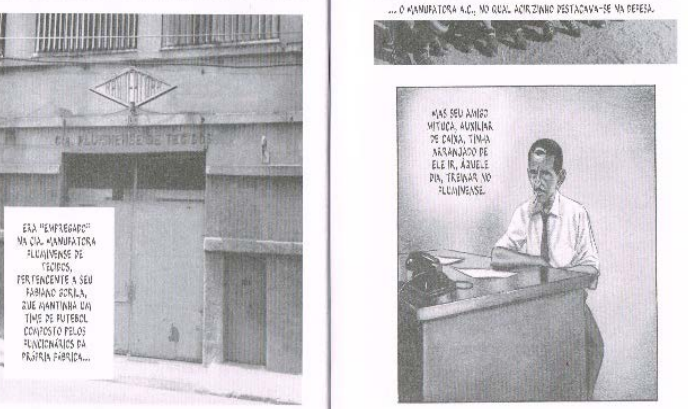
fábricas no contexto da luta pela profissionalização do futebol no Brasil recebe destaque na obra, como aponta Ramon Vitral a partir de uma entrevista com Quintanilha a respeito de Luzes de Niterói, mas que vale também ou ainda mais para Fealdade de Fabiano Gorila:

Uma das intenções de Quintanilha foi enfatizar o que ele chama de "mito do futebol brasileiro oriundo das fábricas". Assim como o Manufatora nasceu dentro da Cia. Manufatora Fluminense de Tecidos, no bairro niteroiense de Barreto, o tradicional Bangu surgiu a partir da Fábrica de Tecidos Bangu, sendo as equipes fabris essenciais para a popularização do futebol no Brasil do início do século 20. ${ }^{20}$

Mais uma vez, está na origem deste elemento narrativo a vida do pai do autor, jogador no Manufatora A.C. e depois no Canto do Rio. Mas a narrativa gráfica eleva esta combinação de fatos e ficção a outro nível e faz com que se destaquem as possibilidades de significação e interpretação a partir do texto-imagem. Esta nova qualidade ficcional é que permite e articula, na leitura crítica, o jogo complexo dos significados no tecido entre política e mito.

\footnotetext{
${ }^{18}$ ANTUNES. O futebol nas fábricas, p. 109.

${ }^{19}$ DAMO; OLIVEN. Fútbol made in Brasil, p. 110.

${ }^{20}$ VITRAL, Dia de caos do pai futebolista inspira HQ do premiado Marcello Quintanilha.
} 


\section{“QUAL FOI SEU ELDORADO?”}

Assim, em poucas imagens e menos palavras, no meio de sua correria pelo centro

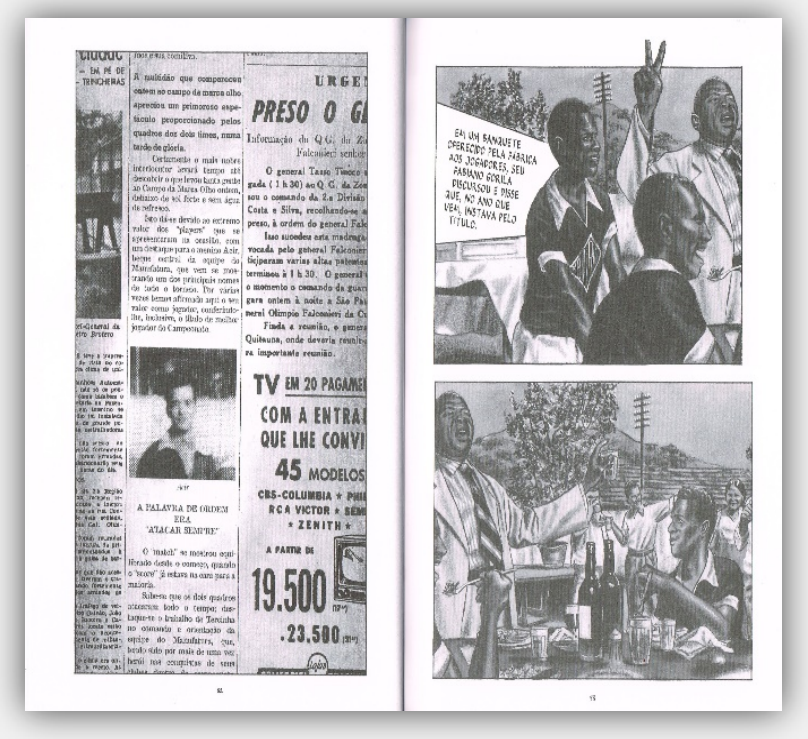
do Rio tumultuado, Acir é retratado como quase-profissional do futebol brasileiro em 1954. A terceira cena concretiza este retrato em poucos painéis que transmitem 0 simbolismo dessa situação, com um "empresário" improvisado e um olhar sobre a suas condições de trabalho. 0 resumo da campanha do Manufatora no campeonato niteroiense (terceiro lugar) inclui a fotocópia de uma página de jornal, noticiando a atuação de Acir numa partida, e realiza um salto no tempo.

Mais de ano se passou e a temática da transferência volta ou continua na cena 4 que mostra um diálogo / duelo de Acir com o pai, que o quer convencer de

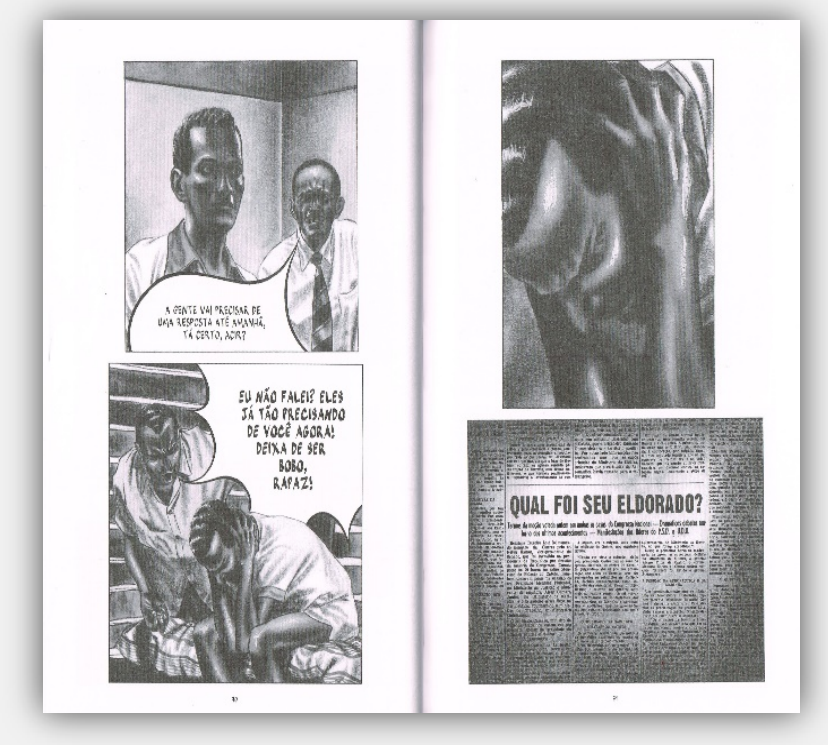
esquecer da oportunidade que Acir acredita poder conseguir no Fluminense e assinar contrato com a Canto do Rio, clube bem mais modesto de Niterói.

0 painel antes daquele da assinatura do contrato nos situa de novo no tempo, com a notícia no jornal sobre o resultado do "Movimento de 11 de Novembro" de 1955: Consegue-se ler que o jornal retratado noticia a votação de impedimento contra o Presidente Café Filho, a pedido do presidente do Senado Nereu Ramos, em 21 de novembro, pedra fundamental para completar o movimento militar liderado por Enrique Lott e 
garantir a posse de Juscelino Kubitschek em janeiro de 1956 como Presidente da República e motor "desenvolvimentista" da grande modernização do Brasil. Este quadro remete à cena 1 e fecha - de forma bem lacônica - a referência à dimensão política que serve como pano de fundo do conto. A manchete "Qual foi seu Eldorado?" refere-se ao discurso de Getúlio Vargas, pronunciado em 27 de setembro de 1933 em Belém do Pará:

Sentimos, talvez persistência do espirito gerador da ficção, que o Eldorado, nesta prodigiosa região do globo, ainda se oculta. Os brasileiros, com esforço continuo e labor disciplinado, hão de descobrilo. A era de ouro prometida surgirá - fruto da riqueza, amadurecido pelo trabalho. E, pela caudal impetuosa, onde Orellana combateu as Amazonas, descerão os tesouros da agricultura e da indústria, para abastecer os mercados do mundo. ${ }^{21}$

Vargas, não por acaso, atualiza o histórico mito da Amazônia como Eldorado, divulgado decisivamente por Francisco de Orellana no século XVI, e o subordina ao

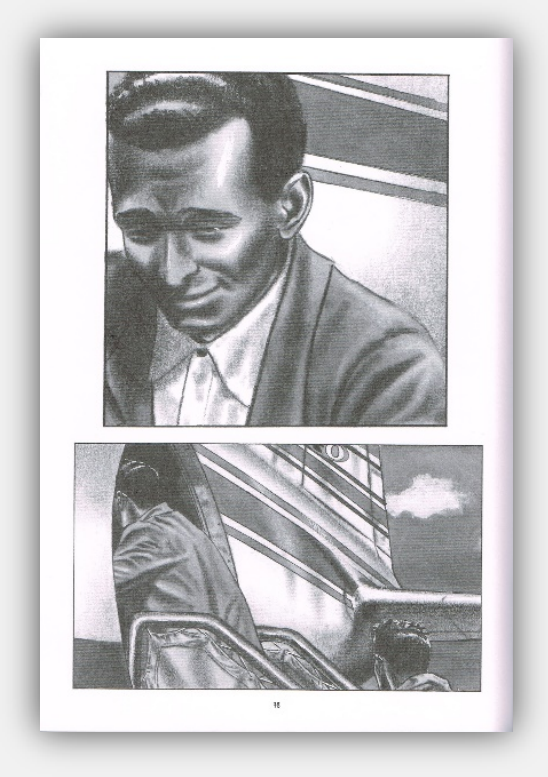
discurso progressista, modernizante da nação brasileira. A ordenação dos painéis, e com ela a sequência narrativa, nos obriga a ligar esta visão política com a carreira ou o destino individual do jogador Acir no Canto do Rio. Outra analogia pelo menos possível, numa leitura crítica das referências e alusões contidas no 'texto' - de novo: nas imagens e na escrita - de Quintanilha, surge dos "tesouros [...], para abastecer os mercados do mundo", com os quais Getúlio indica a "agricultura e indústria" e lembra as legiões de jogadores brasileiros de futebol que saíram do Brasil durante todo o século XX, de forma massiva a partir dos anos 1990, para ganhar a sua vida nos grandes clubes do mundo, mas também em todos os níveis até em campeonatos e ligas inferiores.

Na cena final, Acir parte para uma excursão internacional com o Canto do Rio, e ao subir as escadas, antes de entrar no avião, seu olhar para trás resume a sua trajetória até ali, ao mesmo que implica um olhar para o futuro, os seus sonhos,

\footnotetext{
${ }^{21}$ VARGAS, Discurso pronunciado, na capital do Pará, em 27 de setembro de 1933, p. 394-395.
} 
as suas perspectivas. ${ }^{22}$ Mesmo arriscando um certo patetismo, acredito que não seria exagerado ver neste olhar final também a passagem da dimensão individual do jogador ao futuro do futebol brasileiro.

\section{EPÍLOGO: O FUTURO}

Aqui, meu enfoque se dirigiu à interação entre o esporte enquanto fator sociocultural e a dimensão política concreta enquanto história política brasileira. Mas, nesta obra bastante curta, na literatura mesmo assim denominada de primeiro "romance gráfico" de Marcello Quintanilha, já se vislumbra a extraordinária capacidade que o gênero misturado da HGs possui para tratar do futebol nas suas mais variadas dimensões e facetas. Fealdade de Fabiano Gorila deixa entrever como texto e imagem podem retratar o jogo enquanto jogo (no gramado) e enquanto metáfora (a fuga de Acir pelo Rio, as discussões intensas com o pai).

$\mathrm{Na}$ sua obra, Quintanilha trata repetidas vezes do futebol e explora as possibilidades de expressão das HQ e demostra a sua grande vantagem - pensando agora a partir dos estudos literários - em relação à literatura em sentido tradicional. ${ }^{23}$ Esta expressividade extraordinária na obra de Quintanilha, talvez, tenha a ver com outra qualidade apontada por Paixão Jr. e Franco no seu estudo já citado: "Na prática, o autor questiona e subverte um paradigma das HQs[...]: a página como unidade narrativa. Naquilo que para muitos pode parecer uma heresia, o autor niteroiense transfere esta unidade narrativa para o quadro em si". ${ }^{24}$

No seu mais recente romance gráfico, Luzes de Niterói, o futebol volta a ter protagonismo destacado, como em Fealdade de Fabiano Gorila. Verifica-se tal protagonismo no paratexto e no nível do marketing e da divulgação, ainda mais por se tratar, em 2018, da produção de um autor de HQs já internacionalmente reconhecido. Bem expressiva nesse contexto é a foto que acompanha uma série de

\footnotetext{
${ }^{22}$ QUINTANILHA, Fealdade de Fabiano Gorila, p. 78.

${ }^{23} \mathrm{O}$ futebol aparece na coletânea Hinário Nacional (no 'conto' "Ave Maria, cheia de graça, o Senhor é convosco") como elemento contrastivo dentro de um drama amoroso (duas sequências, QUINTANILHA, Hinário Nacional, p. 8-15 e p. 8-24).

${ }^{24}$ Paixão Júnior / Franco HISTORICIZAR SEMPRE! ANACRONIZAR SEMPRE!, p. 108.
} 
resenhas e entrevistas em torno desse livro, retratando o autor 'bom de bola' fazendo embaixadinhas. ${ }^{25}$

Em Luzes de Niterói, também volta a memória pessoal do pai de Quintanilha,

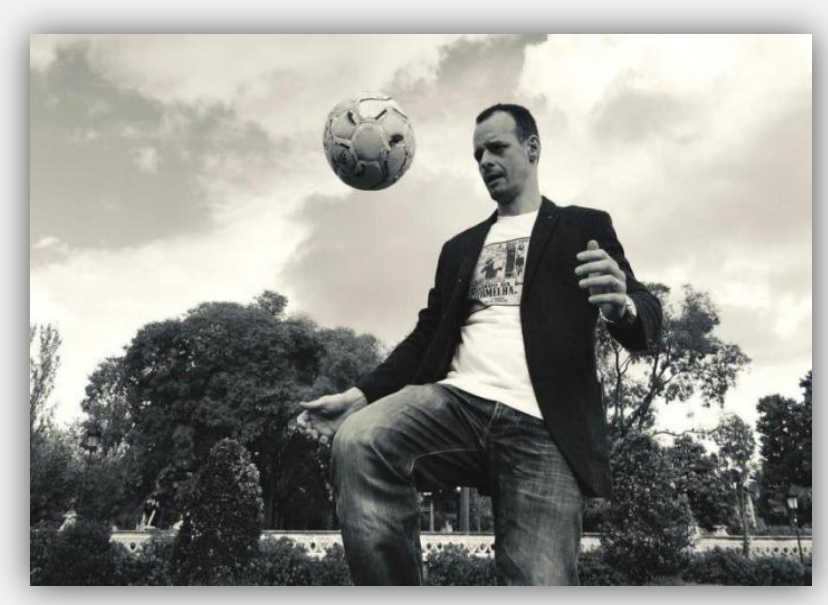
envolvendo - de carta forma - a miniatura de mito, política e futebol analisada em Fealdade de Fabiano Gorila num contexto e numa narrativa desta vez mais individualista e "universalizante" - optando, por exemplo, pela coloração completa e contra a inclusão de outros materiais

(fotografias, cópias), mas sem por isso prescindir da dimensão histórica concreta da narrativa). ${ }^{26}$

Isto se articula principalmente através do intertexto entre as duas narrativas gráficas, a autocitação de alguns quadros e a leve variação de temas do livro de 1999 no de 2018. O quadro da contracapa da edição de 2016 (e que reaparece na página 67) também é incluído (em nova versão) em Luzes de Niterói, ${ }^{27}$ referindo-se a acontecimentos parecidos, aqui o primeiro treino oficial do protagonista Hélcio já contratado pelo Canto do Rio.

Uma referência idêntica nas duas narrativas é o episódio do treino cancelado no dia 24 de agosto de 1954, no areal do Fluminense, que

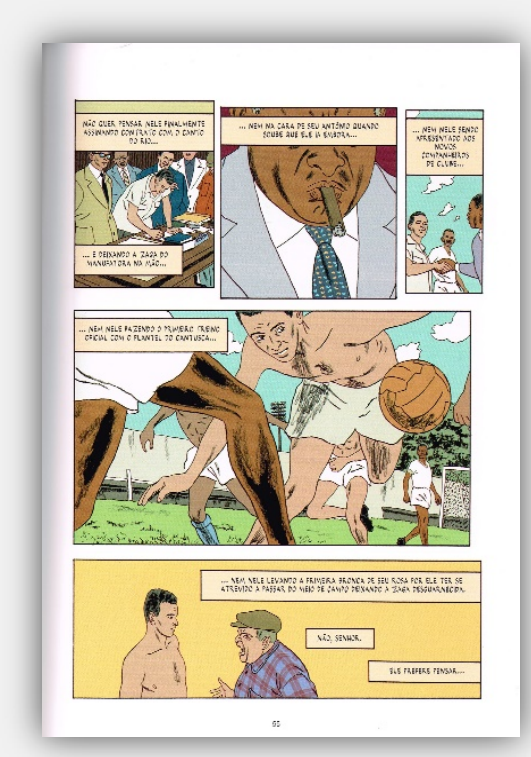
é retratado em Luzes de Niterói de forma sucinta (somente duas páginas) e

\footnotetext{
${ }^{25}$ Luciana de Oliveira / Divulgação, para Luzes de Niterói, 2019.

${ }^{26}$ Em Luzes de Niterói, é a transmissão ao vivo pela rádio que ganha protagonismo e destaque. Assim, o romance gráfico marca o momento histórico da popularização do futebol através da mídia de massas antes do surgimento da transmissão ao vivo do futebol pela televisão em 1956, que iria acrescentar dimensões completamente novas ao fenômeno (cf. BERNECKER / PIETSCHMANN / ZOLLER, Eine kleine Geschichte Brasiliens, p. 260).

${ }^{27}$ QUINTANILHA, Luzes de Niterói, p. 55.
} 
marginal. ${ }^{28}$ Mesmo assim, chama a atenção como as sequências de Fealdade de Fabiano Gorila são retomadas e variadas aqui, incluindo mais dois quadros idênticos, ambos desenhados a partir de seus materiais históricos e introduzindo novos elementos, como a famosa manchete “Só morto sairei do Catete!" e a imagem de um ônibus incendiado em frente à sede do jornal $O$ Globo.
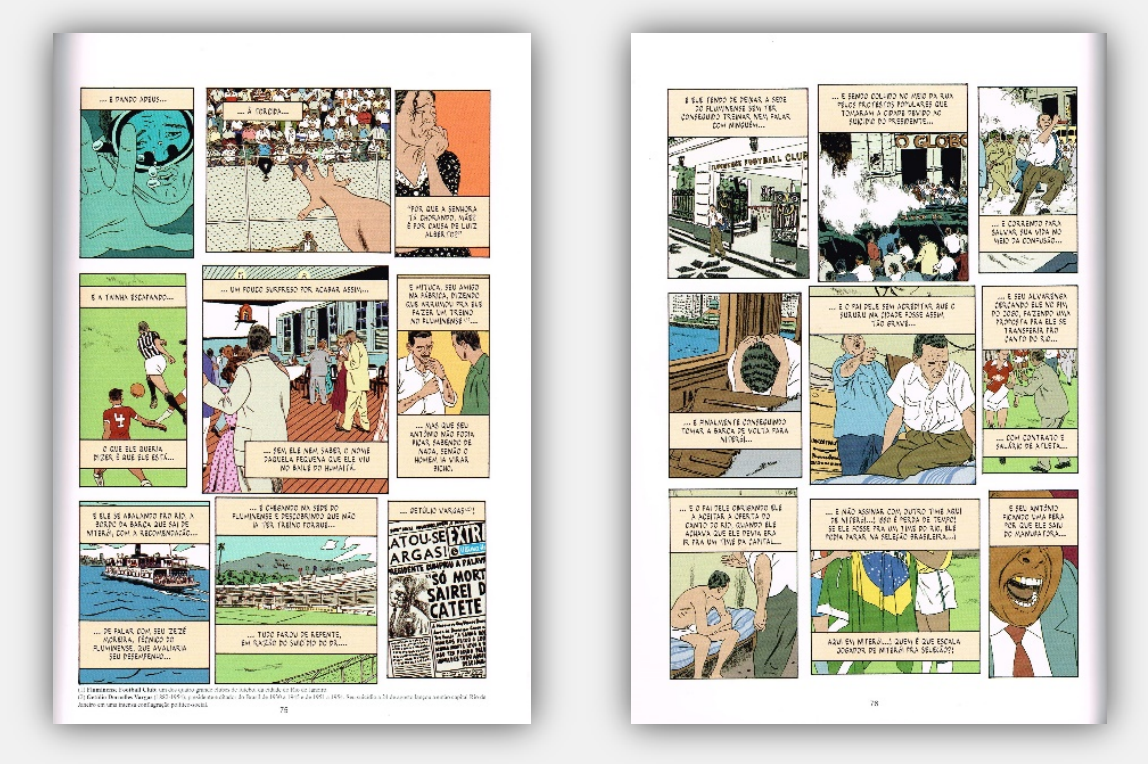

E, neste momento, é preciso parar, mesmo que haja ainda muitos aspectos interessantes a contemplar a partir deste ponto de contato entre as duas narrativas, enfocando um dia na vida de um jogador de futebol niteroiense e representando, em miniatura, a dimensão de mito moderno que possui o futebol no imaginário e na cultural popular brasileira.

\footnotetext{
${ }^{28}$ QUINTANILHA, Luzes de Niterói, p. 75-76.
} 


\section{REFERÊNCIAS}

ANTUNES, Fátima Martin Rodrigues Ferreira. O futebol nas fábricas. Revista USP, n. 22, p. 102-109, 1994.

BARTHES, Roland: Mitologias. 4a ed., trad. Rita Buongermino, Pedro de Souza e Rejane Janowitzer. Rio de Janeiro: DIFEL, 2009.

BARTHES, Roland. Mythologies. Paris: Seuil, 2005.

BERNECKER, Walther L.; PIETSCHMANN, Horst; ZOLLER, Rüdiger. Eine kleine Geschichte Brasiliens. Frankfurt am Main: Suhrkamp, 2000.

CALDAS, Waldemyr. Aspectos sociopolíticos do futebol brasileiro. Revista USP, n. 22, p. 41-49, 1994.

DAMO, Arlei S.; OLIVEN, Rubén G. Fútbol made in Brasil: blanco en las reglas, negro en el estilo. In: LLOPIS GOIG, Ramón (org.). Fútbol postnacional. Transformaciones sociales y culturales del "deporte global" en Europa y en América Latina. Barcelona: Anthropos, 2009, p. 107-128.

FOUCAULT, Michel. Surveillir et punir - Naissance de la prison. Paris: Gallimard, 1975.

FREITAS JÚNIOR, Miguel Archanjo de. No meio do caminho: tensões presentes nas representações sobre o futebol e o ideal de modernidade brasileira na década de 1950. Tese (Doutorado em História). Departamento de História, Universidade Federal do Paraná, Curitiba, 2009. Disponível em: https://bit.ly/39OeSL2. Acesso em: 30 nov. 2019.

HAVEMANN, Nils. Samstags um halb 4. Die Geschichte der Fußballbundesliga. München: Siedler, 2013.

KAZ, Leonel; Costa e Silva, Paulo. Dando tratos à bola: futebol e Brasil. Revista USP, n. 99, p. 67-78, 2013.

PAIXÃO JÚNIOR, Márcio Mário da; FRANCO, Edgar Silveira. HISTORICIZAR SEMPRE! ANACRONIZAR SEMPRE! Duas abordagens de Fealdade de Fabiano Gorila. Esferas, n. 9: Comunicação e quadrinhos, p. 101-110, 2016.

QUINTANILHA, Marcello. Fealdade de Fabiano Gorila. Seguido de Granadilha e de Três minutos de linhas. Lisboa: Polvo, 2016.

QUINTANILHA, Marcello. Hinário nacional. Lisbon: Polvo, 2016.

QUINTANILHA, Marcello. Luzes de Niterói. Lisboa: Polvo, 2018.

PRUTSCH, Ursula; RODRIGUES-MOURA, Enrique. Brasilien. Eine Kulturgeschichte. Bielefeldt: Transcript Verlag, 2013.

SPACA, Rafael (2017): "Não separo desenho e palavra". Na série com grandes quadrinistas brasileiros, Spaca entrevista Marcello Quintanilha. Bravo!, 25/05/2017. Disponível em: https://bit.ly/2N5IRWb. Acesso em: 30 nov. 2019.

THELEWEIT, Klaus. Tor zur Welt. Fußball als Realitätsmodell. Köln: Kiepenheuer \& Witsch, 2004. 
VARGAS, Getúlio. Discurso pronunciado, na capital do Pará, em 27 de setembro de 1933, Brasília: Biblioteca da Presidência da República, s.a.

VITRAL, Ramon (2019): Dia de caos do pai futebolista inspira HQ do premiado Marcello Quintanilha. Páginas coloridas de 'Luzes de Niterói' tratam das origens fabris do futebol brasileiro. Folha de São Paulo, 08/03/2019. Disponível em: https://bit.ly/2ZZdalv. Acesso em: 30 nov. 2019.

Recebido para publicação em: 05 dez. 2019.

Aprovado em: 07 jan. 2020. 